Article

\title{
Droplet Size Distribution Characteristics of Aerial Nozzles by Bell206L4 Helicopter under Medium and Low Airflow Velocity Wind Tunnel Conditions and Field Verification Test
}

\author{
Weixiang Yao ${ }^{1,2}$, Yubin Lan ${ }^{2,3,4, *}$, W. Clint Hoffmann ${ }^{5}$, Jiyu Li ${ }^{1,2}$, Shuang Guo ${ }^{1,2}$, \\ Huihui Zhang ${ }^{6}$ and Juan Wang ${ }^{7}$ \\ 1 College of Engineering, South China Agricultural University, Guangzhou 510642, China; \\ yaoweixiang@stu.scau.edu.cn (W.Y.); lijiyu@scau.edu.cn (J.L.); guoshuang@stu.scau.edu.cn (S.G.) \\ 2 National Center for International Collaboration Research on Precision Agricultural Aviation Pesticides \\ Spraying Technology (NPAAC), Guangzhou 510642, China \\ 3 College of Electronic Engineering, South China Agricultural University, Guangzhou 510642, China \\ 4 Department of Biological and Agricultural Engineering, Texas A\&M University, College Station, \\ TX 77845, USA \\ 5 Prology Consulting LLC, College Station, TX 77845, USA; clint.hoffmann@gmail.com \\ 6 USDA-Agricultural Research Service, Fort Collins, CO 80526, USA; huihui.zhang@usda.gov \\ 7 Mechanical and Electrical Engineering College, Hainan University, Haikou 570228, China; \\ wj-jdxy@hainu.edu.cn \\ * Correspondence: ylan@scau.edu.cn; Tel.: +86-020-8528-1421
}

Received: 7 February 2020; Accepted: 20 March 2020; Published: 23 March 2020

\begin{abstract}
To investigate the spray atomization characteristics of aerial nozzles adapted to manned agricultural helicopters under medium-low airflow velocity $(0$ to $27.8 \mathrm{~m} / \mathrm{s})$ conditions, the droplet size test was carried out in both wind tunnel and field tests. In the wind tunnel test, the laser diffraction device (LDD) was used to test the spray droplet size of CP02, CP03, and CP04 aerial nozzles. A Bell206L4 helicopter was used in the field test. The results in the wind tunnel test showed that due to the nozzles had been used for a long time and the cause of wear, the spray stability of individual nozzles was affected during the test. The limitation of droplet size measurement by using LDD was also found. The field test results showed that the main distribution range of the droplet size measured in the field test was consistent with the results of the wind tunnel test, but the droplet size value was significantly higher and the uniformity of droplet size distribution was poorer than the wind tunnel test value due to the influence of the actual environment. However, the results of field test and wind tunnel test can still be used as a reference for each other.
\end{abstract}

Keywords: manned helicopter; aerial nozzle; wind tunnel; filed test; droplet size distribution; agricultural application

\section{Introduction}

Aerial application, a spraying method with aircraft as the application platform, is one of the most important contents of precision agricultural aviation. Compared with ground machinery, aviation spraying has the advantages of high operating efficiency, a large area of prevention, good control effect, and strong response-ability to a sudden outbreak of pests [1,2]. The essence of aerial applications is the movement process of pesticide after being atomized into small droplets and then settled to the target crop for pest control. However, due to the influence of aviation application equipment, flight 
parameters, and airflow disturbance, drift easily occurs, and droplets will be off from the targets. If not properly controlled, it is easy to harm non-target crops and even cause immeasurable losses [3].

Nozzle is the most critical component in aviation application equipment, and it will directly affect control effect of the application. Droplet size is an indicator of atomization performance, which is also a reference for nozzle design and selection $[4,5]$. Related studies have shown that if the droplet size is too large or too small, it will cause problems such as waste loss or drift and phytotoxicity. Only when the droplet size is in the optimal range, the target crop can capture the droplets and the best control effect can be achieved [6,7]. Therefore, to ensure good aviation spraying effect, it is necessary to carry out detailed measurements to characterize the droplet size distribution of nozzle spray [8]. Wind tunnel test and field test are the most commonly used methods for studying the droplet size distribution. Compared with the field test, the wind tunnel test can accurately simulate the aircraft flight condition by controlling the airflow velocity, less interference from external factors, and repeatability, so it is highly accepted in basic theoretical research related to droplet size [9-13]. However, limited by wind tunnel space size and measurement methods, a wind tunnel test can only study the droplet size distribution near the nozzle, but cannot reflect the droplet size distribution after the droplet is finally in contact with the target. In addition, the secondary rupture may occur in the sedimentation process, which is also impossible to simulate in the wind tunnel test [14]. Therefore, wind tunnel test results are not equivalent to field test results and can only be used as a reference for field test results and a basis for regularity prediction. An optimal research method should combine wind tunnel tests with field tests to obtain the accurate droplet size distribution.

Some scholars have carried out a combination of wind tunnel and field tests on the droplet size distribution. Ferguson et al. $[15,16]$ evaluated the penetration uniformity and drift potential of droplets with different droplet sizes on crop canopy through field experiments, then further quantified the droplet size distribution characteristics and drift potential of each nozzle through wind tunnel test until the appropriate nozzle type was finally selected. Guler et al. [17] compared the droplet size distribution and spray width of air induction nozzles and conventional flat fan nozzles in wind tunnel and greenhouse. Ru et al. [18] conducted the droplet size test of the GP-81A (Civil Aviation Xuzhou Equipment Plants, Xuzhou, JS, China) series aviation nozzles for fixed-wing aircraft in the high-speed wind tunnel, then carried out the field spraying test. The results showed that under the similar spray pressure conditions, the droplet size of the same nozzle has some differences in the two environments, but the distribution trend is consistent. Fritz et al. [19] conducted a wind tunnel test and field test with CP air nozzle (CP Products, Inc., Tempe, AZ, USA), and studied the effects of four different additives on the atomization characteristics and drift on fixed-wing aircraft aerospace spray droplets. Wind tunnel and field tests determined the difference in particle size distribution and drift reduction of different additives, but affected by meteorological conditions and field sampling methods, the field test data was more variable, and it also exposed the problem of poor repeatability in the field test. Li et al. [20] tested the droplet size of XR-Teejet 110015 flat-fan nozzle (Spraying System Co., Chicago, IL, USA) used in quadrotor drones in wind tunnels and field. The results showed that at the wind velocity of $2.5 \mathrm{~m} / \mathrm{s}$, the ratio of droplet size in field test was consistent with that of wind tunnel test, but the value of droplet size was significantly high compared with that in the wind tunnel test.

At present, most studies on the droplets size distribution characteristics are focused on the high-velocity range applicable to manned agricultural fixed-wing aircraft and the low-velocity range applicable to agricultural drones [21,22], few scholars have researched the middle and low-velocity range of manned agricultural helicopters $[23,24]$. In China, most of the helicopters and ancillary equipment for aviation spraying come from abroad, there is a lack of actual application performance testing for various types of machines and equipment. Due to the lack of study on the applicability of these devices in China [25], it is necessary to find out the spraying regular of manned agricultural helicopters under medium-low velocity category.

The objective of this study was to draw on the respective advantages of wind tunnel test and field test, understand the droplet size distribution characteristics of the manned agricultural helicopters and 
their associated flat-fan nozzles commonly used in China, and try to find the relationship between droplet size spectra and stains/impacts dimension. Finally, it is expected to optimize the aviation application mode, provide data support for the nozzles selection of helicopter under medium-low velocity, and provide a reference for precise spray application.

\section{Materials and Methods}

\subsection{Test Method and Object}

This test consisted of two parts: the wind tunnel simulation test and field verification test. The tested aerial nozzles were hydraulic CP flat nozzles (CP Products, Inc., Tempe, AZ, USA) used by a Bell206L4 helicopter (Bell Helicopter Textron Inc., Fort Worth, TX, USA) in the daily spraying operation. The nozzle types were $\mathrm{CP} 02, \mathrm{CP} 03$, and $\mathrm{CP} 04$, the equivalent orifice size $(1.0 \mathrm{~mm}, 1.3 \mathrm{~mm}$, and $1.4 \mathrm{~mm}$ ) increases sequentially with a spray fan angle of $80^{\circ}$.

\subsection{Wind Tunnel Simulation Test Section}

\subsubsection{Wind Tunnel}

The wind tunnel used in the test was a high-low speed composite wind tunnel for agricultural aviation in the National Center for International Collaboration Research on Precision Agricultural Aviation Pesticides Spraying Technology (NPAAC) of South China Agricultural University (SCAU) in Guangzhou, Guangdong, China. The wind tunnel adopted direct current closed design based on the ISO 22856 standard [26]. It was mainly composed of six parts: power section, transition section, diffusion section, stable section, contraction section, and test section. The wind tunnel body was an all-steel structure with observation windows and a spray operating platform on both sides. A movable or adjustable spray track was provided in the wind tunnel hole body to meet the requirements of conventional spray testing. The detailed technical indicators of the wind tunnel are shown in Table 1, and the physical picture of the wind tunnel is shown in Figure 1.

Table 1. Parameters of South China Agricultural University (SCAU) wind tunnel.

\begin{tabular}{cc}
\hline Main Parameter & Norms and Numerical \\
\hline Diameter of test section $(\mathrm{m} \times \mathrm{m} \times \mathrm{m})$ & $20 \times 2.0 \times 1.1$ \\
Wind velocity $\left(\mathrm{m} \cdot \mathrm{s}^{-1}\right)$ & $2-52$ \\
Turbulence intensity $(\%)$ & $<1$ \\
Axial static pressure gradient & $<0.01$ \\
Dynamic pressure stability coefficients $(\%)$ & $<1$ \\
Averaged flow inclination angle $\left({ }^{\circ}\right)$ & $<1$ \\
\hline
\end{tabular}

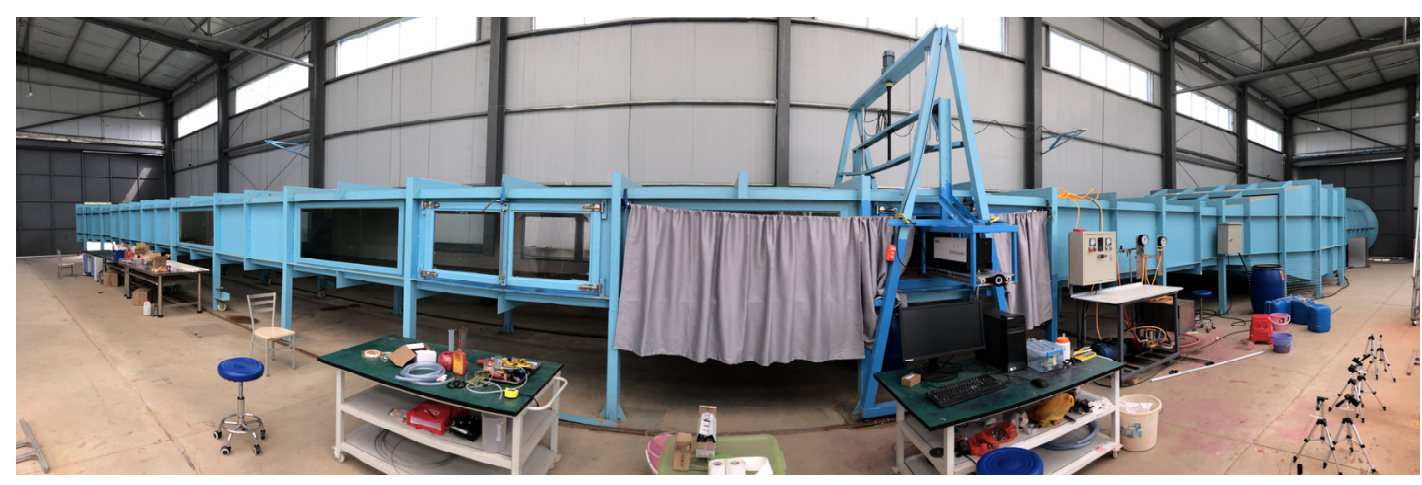

Figure 1. SCAU wind tunnel. 


\subsubsection{Spray Test Design of Wind Tunnel}

The spray control system used in the test was designed by the NPACC independently. The system included water tank, relief valve, boost pump, pressure gauge, pressure reducing valve, flow meter, and nozzles. The spray pressure was regulated in two stages with a safety valve and a pressure reducing valve for precise adjustment of the spray pressure in the range of $100-500 \mathrm{kPa}(14-73 \mathrm{psi})$.

The nozzles tested were randomly selected from the helicopter spray rod and three nozzles were selected for each type. The three CP-02 nozzles were named CP02-1, CP02-2, and CP02-3; the CP-03 nozzles were named CP03-1, CP03-2, and CP03-3; the CP-04 nozzles were named CP04-1, CP04-2, and CP04-3. All test nozzles had been used for more than three years (Figure 2).

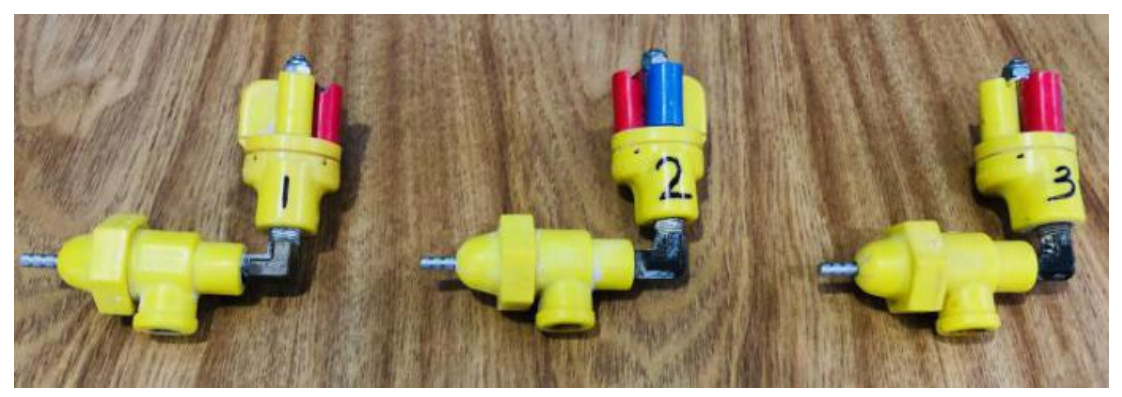

Figure 2. Nozzles tested.

The droplet size distribution was measured by DP-02 laser diffraction device (LDD) (Zhuhai OMEC Instrument Co., Ltd, Zhuhai, China). The emitter and receiver of LDD were horizontally placed on the special working platform at the observation windows on both sides of the wind tunnel test section. The laser had 48 independent detection units with the sampling time less than or equal to $2 \mathrm{~min}$, the measurement range was 1 to $1500 \mu \mathrm{m}$, and the median diameter repeatability accuracy was $\pm 3 \%$. After each measurement, the droplets size test report can be generated. The nozzles were placed horizontally, $55 \mathrm{~cm}$ from the upper and lower layers of the wind tunnel, and $95 \mathrm{~cm}$ from the LLD. The spray plume was in the same horizontal plane with the laser line and spaced $40 \mathrm{~cm}$ apart. The spray plume was perpendicular to the laser line and paralleled to the wind tunnel observation window (Figure 3).

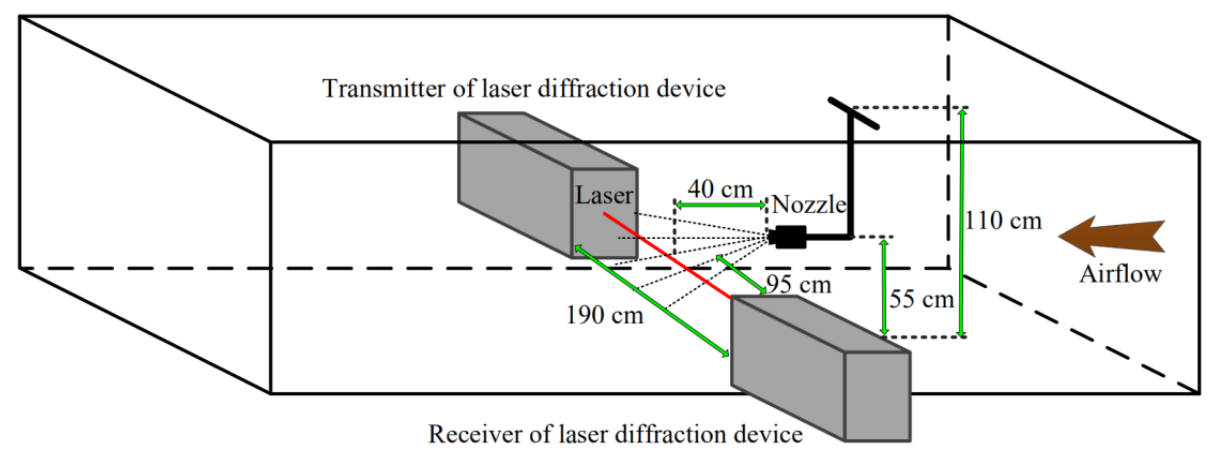

Figure 3. Schematic of the spray test layout.

According to the medium and low flight velocities of the helicopter's daily operation, six constant airflow velocities were set in the wind tunnel test, $0 \mathrm{~m} / \mathrm{s}(0 \mathrm{~km} / \mathrm{h}), 16.7 \mathrm{~m} / \mathrm{s}(60 \mathrm{~km} / \mathrm{h}), 19.4 \mathrm{~m} / \mathrm{s}(70 \mathrm{~km} / \mathrm{h})$, $22.2 \mathrm{~m} / \mathrm{s}(80 \mathrm{~km} / \mathrm{h}), 25.0 \mathrm{~m} / \mathrm{s}(90 \mathrm{~km} / \mathrm{h})$, and $27.8 \mathrm{~m} / \mathrm{s}(100 \mathrm{~km} / \mathrm{h})$, among which the $0 \mathrm{~m} / \mathrm{s}$ was used as a static comparison reference. At the same time, according to the actual spray pressure of each nozzle during helicopter spraying operation, the spray pressure of $\mathrm{CP} 02, \mathrm{CP} 03$ and $\mathrm{CP} 04$ were set as $345 \mathrm{kPa}$ (50 psi), $330 \mathrm{kPa}(48 \mathrm{psi})$, and $310 \mathrm{kPa}(45 \mathrm{psi})$, respectively. 
Before the wind tunnel test, each nozzle was installed on the spray track and connected with the spray system for a flow test. Each nozzle was measured five times by SC-1 flow meter (Rittenhouse Company Inc., Philadelphia, PA, USA), and the average value was recorded as the spray flow rate. After the flow measurement, the droplet size was measured by LDD. The room temperature and air humidity were kept constant during the test, and the test reagent was water. Each test was repeated at least three times with a test time of 30 seconds to ensure that the standard deviation of the droplet size data of the same group was not greater than $10 \%$ [5].

\subsection{Field Verification Test Section}

\subsubsection{Manned Helicopter and Carrying Equipment}

The helicopter used in field test was Bell206L4 (Figure 4), equipped with a Simplex model 7900 (Simplex Manufacturing Company Inc., Auburn, AL, USA) spray system for precision variable-rate spraying control. Simultaneously. A total of $51 \mathrm{CP}$ nozzles were installed in the aircraft, of which 6 nozzles (spacing of $17 \mathrm{~cm}$ ) were installed below the belly in a vertical downward direction, and 45 nozzles (spacing of $15 \mathrm{~cm}$ ) were installed on the boom in a horizontal backward direction. An airborne BeiDou real time kinematic (RTK) differential system developed by SCAU with the function of RTK differential positioning was also equipped, which can record flight parameters in real-time and draw actual operation trajectory as references of the spraying effect. The specification of the helicopter and carrying equipment are listed in Table 2.

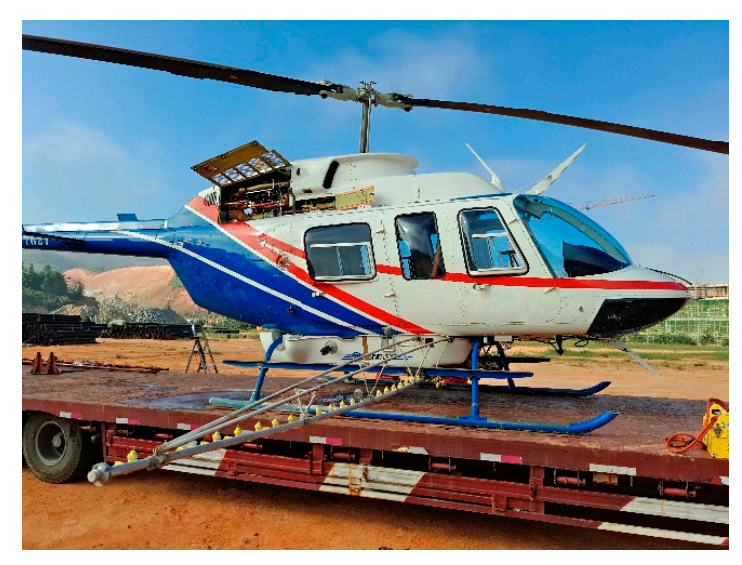

Figure 4. Bell206L4 helicopter for spraying operation.

Table 2. Technical parameters of Bell206L4 helicopter and main performance indexes of equipped equipment.

\begin{tabular}{cc}
\hline Main Parameter & Norms and Numerical Value \\
\hline Airframe length $(\mathrm{m})$ & 10.56 \\
Airframe height $(\mathrm{m})$ & 3.04 \\
Main rotor/Tail rotor diameter $(\mathrm{m})$ & $11.28 / 1.65$ \\
Maximum load $(\mathrm{L})$ & 600 \\
Maximum velocity $(\mathrm{km} / \mathrm{h})$ & 241 \\
Empty weight $(\mathrm{kg})$ & 1057 \\
Max. takeoff weight $(\mathrm{kg})$ & 2064 \\
Boom length $(\mathrm{m})$ & 8.60 \\
Nozzle quantity & 51 \\
Spray width $(\mathrm{m})$ & $25-40$ \\
Pesticide tank size $(\mathrm{m} \times \mathrm{m} \times \mathrm{m})$ & $3.40 \times 1.20 \times 0.45$ \\
Working performance $\left(\mathrm{hm}{ }^{2} / \mathrm{h}\right)$ & $\mathrm{Simplex}$ \\
Spray system & $\left(10+5 \times \mathrm{D} \times 10^{-7}\right)^{[\mathrm{a}]}$ \\
BeiDou plane accuracy $(\mathrm{mm})$ & $\left(20+1 \times \mathrm{D} \times 10^{-6}\right)^{[\mathrm{a}]}$ \\
BeiDou elevation accuracy $(\mathrm{mm})$ &
\end{tabular}

${ }^{[a]} \mathrm{D}$ represents actual distance measured by BeiDou differential system, $\mathrm{km}$. 


\subsubsection{Test Site and Layout}

The experiment was conducted in Qulai Town $\left(114^{\circ} 55^{\prime} \mathrm{E}, 27^{\circ} 05^{\prime} \mathrm{N}\right)$ of Ji'an City, Jiangxi Province, China. The test site was a wide field of vision without shelters, and the main spraying area was grassland with a grass height of 5-10 $\mathrm{cm}$. As shown in Figure 5, according to the wind direction and the maximum effective spray width, three parallel 40-m long sampling lines were at a distance of $40 \mathrm{~m}$ apart and perpendicular to the wind direction in the spraying area. Each sampling line was marked in the order of -20 to $20 \mathrm{~m}$ from west to east (W-E), and the droplet collection card was placed at an interval of $1 \mathrm{~m}$. The sampling point $0 \mathrm{~m}$ was on the helicopter route, which is north to south (N-S) parallel to the wind direction. One-way spraying operation (1\#-3\#) was carried out three times in a sequence of nozzle $\mathrm{CP} 02, \mathrm{CP} 03$, and $\mathrm{CP} 04$. The flight height and velocity of all three tests were set as $11 \mathrm{~m}$ and $16.7 \mathrm{~m} / \mathrm{s}(60 \mathrm{~km} / \mathrm{h})$ according to actual operating experience.

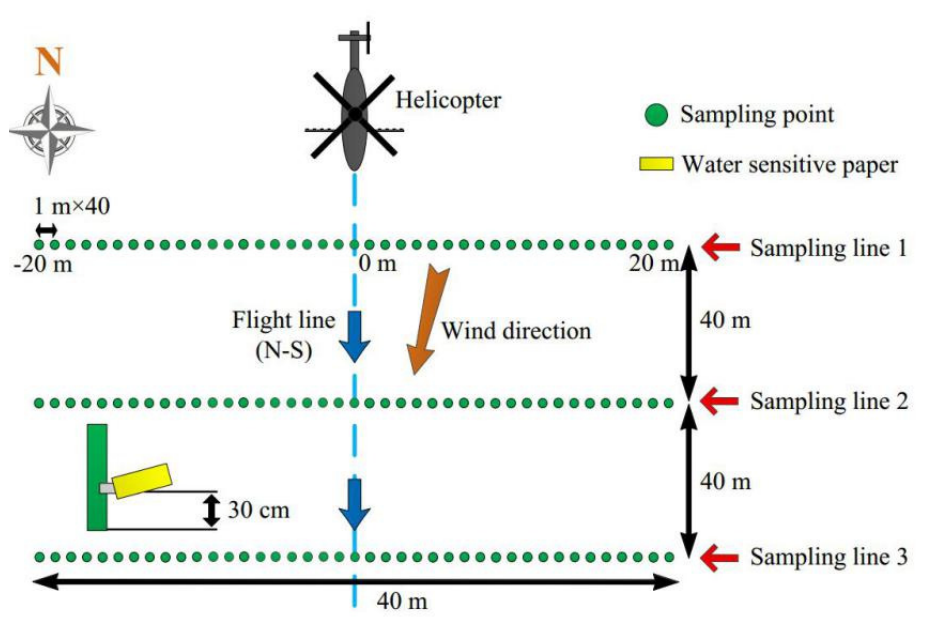

Figure 5. Schematic diagram of field test.

The experiment used the mass fraction of $5 \%$ urea aqueous solution $400 \mathrm{~L}$ instead of liquid pesticide for spraying. The droplet collection card, $80 \mathrm{~mm} \times 30 \mathrm{~mm}$, was made of water-sensitive paper (WSP) (Chongqing Liuliushanxia Plant Protection Technology Co., Ltd, Chongqing, China), and placed at a height of $30 \mathrm{~cm}$ from the ground. Simultaneously, a Kestrel 5500 Link micro meteorological station (Nielsen-Kellerman Co., Boothwyn, PA, USA) was located at a height of $2 \mathrm{~m}$ above ground and $40 \mathrm{~m}$ far away from the route. The weather data, such as wind velocity, wind direction, temperature, and humidity in the natural environment, were recorded every 2 seconds during the test.

After each spray application test, the WSPs were immediately gathered and put into marked envelopes and placed in a cool place to be brought back to the laboratory later. Then WSPs were analyzed by using image processing software DepositScan (USDA. Wooster, MA, USA) to obtain droplet data of each sampling point.

\subsection{Evaluation Parameter}

The parameters for evaluating the atomization performance of the nozzle are $D_{V 0.1}, D_{V 0.5}, D_{V 0.9}$, $V_{<100}\left(\%_{\text {vol }}\right)$, coefficient of variation $(C V)$, and relative span $(R S)$ [8]. The $D_{V a}$ value is the droplet diameter $(\mu \mathrm{m})$ where $(\mathrm{a} \times 100) \%$ of the spray volume is accumulated in droplets smaller than this value. $D_{V 0.5}$ is also called volume median diameter (VMD), which is the most commonly used index to measure droplet size. $V_{<100}\left(\%_{\text {vol }}\right)$ expresses the percent spray volume with a diameter less than $100 \mu \mathrm{m}$. The $C V$ is used to characterize the uniformity of droplet distribution. The smaller $C V$ is, the more uniform the droplet distribution is. $R S$ is the span of the droplet distribution, which reflects the uniformity of the droplets sprayed by the nozzle. The smaller the RS, the better the atomization of the droplets. The calculation formula of $R S$ is: 


$$
R S=\frac{D_{V 0.9}-D_{V 0.1}}{D_{v 0.5}}
$$

\section{Results and discussion}

\subsection{Wind Tunnel Test}

\subsubsection{Nozzle Flow Rate}

The flow test result (Table 3) showed that under the corresponding spray pressure, the actual measured spray flow rates of most nozzles per unit time were close to the standard flow reference value. Only CP04-1 and CP04-3 nozzle had a large deviation from the standard flow reference value of $0.47 \mathrm{~L} / \mathrm{min}$ and $0.32 \mathrm{~L} / \mathrm{min}$, respectively. It was speculated that this nozzle orifice has become enlarged due to a normal wear condition over time.

Table 3. CP nozzle flow rates of the three selected nozzles used in the droplet size test.

\begin{tabular}{cccc}
\hline \multirow{2}{*}{ Number of Nozzles } & \multirow{2}{*}{ Pressure (kPa) } & \multicolumn{2}{c}{ Flow Rate (L/min) } \\
& & Measured & 1.02 \\
Reference ${ }^{\text {aa] }}$
\end{tabular}

[a] The reference value was provided by the official website of the CP nozzle.

\subsubsection{Variation of Droplet under Different Airflow Velocities}

Figure 6 shows the variation of $D_{V 0.1}, D_{V 0.5}$, and $D_{V 0.9}$ for the three types nozzles at different airflow velocities. The droplets sizes of the $\mathrm{CP} 02, \mathrm{CP} 03$, and CP04 nozzles showed a significant step-like difference. Taking $D_{V 0.9}$ as an example, the $D_{V 0.9}$ average values of the three types of nozzles were $366.6 \mu \mathrm{m}$ (CP02), $524.7 \mu \mathrm{m}$ (CP03), and $648.6 \mu \mathrm{m}$ (CP04,) respectively, due to the different orifice sizes. It was also found that the $D_{V 0.1}$ and $D_{V 0.5}$ values of the corresponding three types nozzles showed a steady increase trend with the airflow velocity increases from $0 \mathrm{~m} / \mathrm{s}$ to $27.8 \mathrm{~m} / \mathrm{s}$. However, the value of $D_{V 0.9}$ was of great volatility, even the same type of nozzles showed obvious differences. According to the statistical analysis, the maximum difference of $D_{V 0.9}$ was between CP04- 1 and CP04- 2 when the airflow velocity was $22.2 \mathrm{~m} / \mathrm{s}$ (Fig. 6c), up to $259.4 \mu \mathrm{m}$, but it also showed a trend of increasing with the airflow velocity.

The reason why the droplets size variation fluctuated greatly was mainly due to the performance problem with the tested nozzles. The tested nozzles had been used for a long time, and there was some wear, which may lead to a large deviation of the spray in the repeated test. It was inevitable for older non-reference nozzles. Secondly, studies had shown that laser measurement using LDD had sampling bias and certain limitations under different airflow conditions. In the absence or low airflow velocity, small droplets will be measured multiple times, resulting in a small measurement of the droplet size. Therefore, it appeared that the measured droplet size increased with the airflow velocity increased, which was similar to the results in Fritz's [27]. In addition, it was also related to the principle of liquid atomization of the pressure nozzle. The formation of droplets in the pressure nozzle depended on the fracture of the flat liquid film. In essence, the generation of fine droplets was caused by the aerodynamic fragmentation of the relative movement between the two phases (liquid phase and surrounding gas medium). The most important parameter affecting the droplet stability was the 
nondimensional Weber number. As the airflow velocity increased, the flat liquid film was gradually increased by the shearing force of the air, the droplets deformation rate accelerated, and the Weber number also increased. When a certain critical state was reached, the surface tension was not enough to resist the liquid flow, the droplets were continuously stretched, so that the droplets were more likely to be broken and secondary broken, and the droplet size changed. Some studies also showed that for different types of nozzles, when the Weber number was the same, the larger the droplet size, the lower the relative gas/liquid velocity. As a result, the deformation rate of the larger size droplets was slightly lower than that of the smaller size droplets. Moreover, in the above process, there were accompanied by the effect of droplet dispersion and droplet aggregation. The interaction of the two effects on the droplets also caused a series of uncontrollable changes in droplets size [28,29].

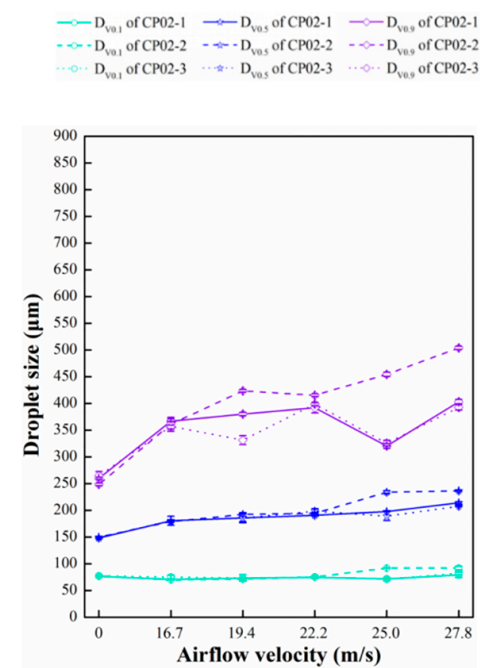

(a)

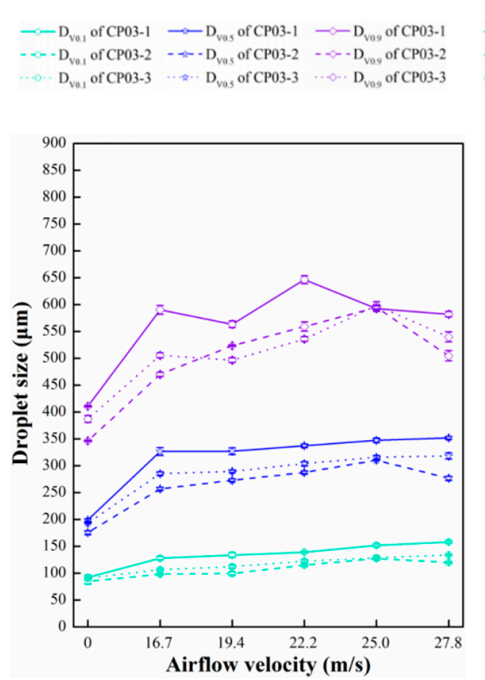

(b)

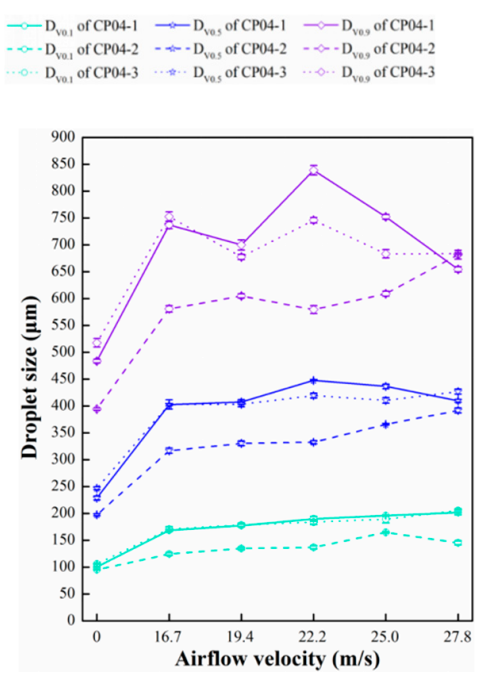

(c)

Figure 6. (a) Variation of $D_{V 0.1}, D_{V 0.5}$, and $D_{V 0.9}$ of CP02 nozzle with the airflow velocity; (b) variation of $D_{V 0.1}, D_{V 0.5}$, and $D_{V 0.9}$ of CP03 nozzle with the airflow velocity; (c) variation of $D_{V 0.1}, D_{V 0.5}$, and $D_{V 0.9}$ of CP04 nozzle with the airflow velocity.

Except for the droplets size, other spray parameters of each nozzle were also affected by the change of airflow velocity. Table 4 shows the $V_{<100}\left(\%_{\text {vol }}\right)$ and $R S$ for each nozzle at six different airflow velocities. It can be seen from Table 4 that as the airflow velocity increased, the measured values of $V_{<100}\left(\%_{\text {vol }}\right)$ of each nozzle showed a trend of decrease. The $V_{<100}\left(\%_{\text {vol }}\right)$ range of each nozzle were $7.8 \%$ (CP02), $10.8 \%$ (CP03) and 8.4\% (CP04). However, the RS regularity of each type nozzle was not obvious. Under each airflow velocity, the $R S$ for the CP02 nozzle was in the range of $1.22(0 \mathrm{~m} / \mathrm{s})$ to $1.68(22.2 \mathrm{~m} / \mathrm{s})$; for CP03 nozzle was in the range of $1.29(27.8 \mathrm{~m} / \mathrm{s})$ to $1.54(0 \mathrm{~m} / \mathrm{s})$; and for CP04 nozzle was within the range of $1.20(27.8 \mathrm{~m} / \mathrm{s})$ to $1.62(0 \mathrm{~m} / \mathrm{s})$. In addition, for the three nozzles of the same type, the spray parameters also showed different significant differences under different airflow velocities, which was especially evident on CP02-2, CP03-2, and CP04-2. These were consistent with the droplet size change results in Figure 6. The relevant trend changes can also be explained by the above-mentioned reason analysis.

It can also be seen from the above analysis that in selecting the aviation nozzle, the quality of the nozzle should be strictly controlled to reduce the spray deviation and achieve the best spraying effect. When the nozzle is used for a certain period of time, it must be replaced. Otherwise, the spraying performance will become unstable. 
Table 4. Related droplet parameter for spray measured at six airflow velocities for each type of the three individual nozzles.

\begin{tabular}{|c|c|c|c|c|c|c|c|c|c|c|c|c|}
\hline \multirow[b]{2}{*}{ Nozzle Type } & \multicolumn{2}{|c|}{$0 \mathrm{~m} / \mathrm{s}$} & \multicolumn{2}{|c|}{$16.7 \mathrm{~m} / \mathrm{s}$} & \multicolumn{2}{|c|}{$19.4 \mathrm{~m} / \mathrm{s}$} & \multicolumn{2}{|c|}{$22.2 \mathrm{~m} / \mathrm{s}$} & \multicolumn{2}{|c|}{$25 \mathrm{~m} / \mathrm{s}$} & \multicolumn{2}{|c|}{$27.8 \mathrm{~m} / \mathrm{s}$} \\
\hline & $\begin{array}{c}V_{<100} \\
\left(\%_{\text {vol }}\right)\end{array}$ & RS & $\begin{array}{c}V_{<100} \\
\left(\%_{\text {vol }}\right)\end{array}$ & $R S$ & $\begin{array}{c}V_{<100} \\
\left(\%_{\text {vol }}\right)\end{array}$ & $R S$ & $\begin{array}{c}V_{<100} \\
\left(\%_{\text {vol }}\right)\end{array}$ & $R S$ & $\begin{array}{c}V_{<100} \\
\left(\%_{\text {vol }}\right)\end{array}$ & $R S$ & $\begin{array}{c}V_{<100} \\
\left(\%_{\text {vol }}\right)\end{array}$ & $R S$ \\
\hline СР02-1 & $24.0 \pm 0.7 a$ & $1.24 \pm 0.02 a$ & $22.6 \pm 0.4 \mathrm{ab}$ & $1.64 \pm 0.04 a$ & $20.8 \pm 0.6 b$ & $1.65 \pm 0.06 b$ & $20.1 \pm 0.4 a$ & $1.69 \pm 0.02 \mathrm{ab}$ & $19.8 \pm 0.3 b$ & $1.26 \pm 0.02 \mathrm{c}$ & $17.0 \pm 0.5 a$ & $1.52 \pm 0.01 b$ \\
\hline СР02-2 & $23.9 \pm 0.2 a$ & $1.14 \pm 0.02 b$ & $23.0 \pm 0.4 a$ & $1.63 \pm 0.04 a$ & $20.5 \pm 0.4 b$ & $1.83 \pm 0.02 \mathrm{a}$ & $19.8 \pm 0.4 a$ & $1.75 \pm 0.01 \mathrm{a}$ & $14.1 \pm 0.1 \mathrm{c}$ & $1.55 \pm 0.00 \mathrm{a}$ & $13.1 \pm 0.7 b$ & $1.74 \pm 0.00 \mathrm{a}$ \\
\hline $\mathrm{CP} 02-3$ & $22.7 \pm 0.4 b$ & $1.27 \pm 0.05 a$ & $22.2 \pm 0.3 b$ & $1.56 \pm 0.07 a$ & $21.9 \pm 0.7 \mathrm{a}$ & $1.39 \pm 0.05 c$ & $20.1 \pm 0.8 \mathrm{a}$ & $1.60 \pm 0.08 b$ & $21.1 \pm 0.4 \mathrm{a}$ & $1.35 \pm 0.03 b$ & $17.1 \pm 0.6 \mathrm{a}$ & $1.5 \pm 0.02 b$ \\
\hline Mean value & 23.5 & 1.22 & 22.6 & 1.61 & 21.1 & 1.62 & 20.0 & 1.68 & 18.3 & 1.39 & 15.7 & 1.59 \\
\hline СР03-1 & $14.5 \pm 1.2 \mathrm{~b}$ & $1.60 \pm 0.03 a$ & $6.2 \pm 0.5 c$ & $1.42 \pm 0.04 a$ & $6.5 \pm 0.1 c$ & $1.32 \pm 0.05 b$ & $5.2 \pm 0.1 c$ & $1.51 \pm 0.01 \mathrm{~b}$ & $4.3 \pm 0.3 b$ & $1.27 \pm 0.01 \mathrm{~b}$ & $3.5 \pm 0.4 \mathrm{c}$ & $1.21 \pm 0.02 c$ \\
\hline СР03-2 & $18.3 \pm 2.2 \mathrm{a}$ & $1.49 \pm 0.06 \mathrm{~b}$ & $11.8 \pm 0.2 \mathrm{a}$ & $1.45 \pm 0.04 a$ & $10.3 \pm 0.4 a$ & $1.56 \pm 0.03 a$ & $7.8 \pm 0.4 a$ & $1.55 \pm 0.02 \mathrm{a}$ & $6.1 \pm 0.3 a$ & $1.51 \pm 0.02 \mathrm{a}$ & $6.8 \pm 0.2 a$ & $1.39 \pm 0.02 a$ \\
\hline СР03-3 & $15.1 \pm 0.7 \mathrm{~b}$ & $1.54 \pm 0.02 \mathrm{ab}$ & $9.7 \pm 0.1 b$ & $1.40 \pm 0.02 \mathrm{a}$ & $9.2 \pm 0.1 b$ & $1.31 \pm 0.04 b$ & $6.9 \pm 0.3 b$ & $1.36 \pm 0.01 c$ & $6.5 \pm 0.4 a$ & $1.49 \pm 0.03 a$ & $5.3 \pm 0.1 b$ & $1.28 \pm 0.01 b$ \\
\hline Mean value & 16.0 & 1.54 & 9.2 & 1.42 & 8.7 & 1.40 & 6.6 & 1.47 & 5.6 & 1.42 & 5.2 & 1.29 \\
\hline CP04-1 & $10.9 \pm 0.2 b$ & $1.68 \pm 0.03 a$ & $3.0 \pm 0.1 b$ & $1.41 \pm 0.02 \mathrm{a}$ & $2.6 \pm 0.2 c$ & $1.28 \pm 0.02 b$ & $2.5 \pm 0.1 b$ & $1.45 \pm 0.02 \mathrm{a}$ & $2.4 \pm 0.1 b$ & $1.27 \pm 0.02 \mathrm{a}$ & $1.5 \pm 0.1 b$ & $1.10 \pm 0.01 \mathrm{~b}$ \\
\hline СР04-2 & $12.6 \pm 0.4 \mathrm{a}$ & $1.52 \pm 0.01 \mathrm{~b}$ & $7.1 \pm 0.4 a$ & $1.44 \pm 0.03 a$ & $5.7 \pm 0.4 a$ & $1.42 \pm 0.03 a$ & $5.5 \pm 0.6 a$ & $1.33 \pm 0.00 b$ & $2.9 \pm 0.0 a$ & $1.22 \pm 0.01 \mathrm{~b}$ & $4.7 \pm 0.3 a$ & $1.37 \pm 0.05 a$ \\
\hline СР04-3 & $9.3 \pm 0.2 \mathrm{c}$ & $1.67 \pm 0.01 \mathrm{a}$ & $3.5 \pm 0.2 b$ & $1.46 \pm 0.00 \mathrm{a}$ & $3.6 \pm 0.1 b$ & $1.24 \pm 0.01 b$ & $2.9 \pm 0.2 b$ & $1.34 \pm 0.01 b$ & $2.3 \pm 0.2 b$ & $1.20 \pm 0.02 b$ & $1.8 \pm 0.3 b$ & $1.12 \pm 0.02 b$ \\
\hline Mean value & 10.9 & 1.62 & 4.5 & 1.44 & 4.0 & 1.31 & 3.6 & 1.37 & 2.5 & 1.23 & 2.7 & 1.20 \\
\hline
\end{tabular}

Means \pm standard deviations within each nozzle type and droplet parameter grouping followed by the same letter are not significantly different as determined using SPSS 16.0 ( $p<0.05$

Duncan's Test). 


\subsection{Field Test}

\subsubsection{Meteorological and Flight Parameter Data}

The light airborne Beidou RTK differential system can accurately record the time of each flight and the flight parameter data of the helicopter, and the micro weather station recorded the meteorological data every $2 \mathrm{~s}$. Corresponding to the data recorded by the Beidou system and the data of the micro weather station, the weather data and flight parameters of each test are shown in Table 5. During the test, the wind velocity, temperature, and humidity had been relatively stable. The wind velocity was maintained in the breeze range of $0.5-1.2 \mathrm{~m} / \mathrm{s}$, the average temperature was $17.2^{\circ} \mathrm{C}$, and the average relative humidity was $72.3 \%$. At the same time, the parameters of each flight operation were also normal, and the average flight height was $11.54 \mathrm{~m}$, with the variation range of $1.24 \mathrm{~m}$. The average flight velocity was maintained in the range of $16.36-17.58 \mathrm{~m} / \mathrm{s}$, and the real-time flight speed of the same flight over three droplet collecting belts was relatively close. The spray volume application rates were $12.83 \mathrm{~L} / \mathrm{ha}(1 \#), 18.49 \mathrm{~L} / \mathrm{ha}(2 \#)$, and $28.58 \mathrm{~L} / \mathrm{ha}(3 \#)$, respectively. In addition, the effective spraying distance of each sorting was more than $130 \mathrm{~m}$, which met the test design requirements.

Table 5. Summary of meteorological data and flight parameters for each test.

\begin{tabular}{cccccccc}
\hline Test & $\begin{array}{c}\text { Wind Velocity and } \\
\text { Wind Direction } \\
(\mathbf{m} / \mathbf{s})\end{array}$ & $\begin{array}{c}\text { Temperature } \\
\left({ }^{\circ} \mathbf{C}\right)\end{array}$ & $\begin{array}{c}\text { Humidity } \\
\mathbf{( \% )}\end{array}$ & $\begin{array}{c}\text { Flight } \\
\text { Height } \\
(\mathbf{m})\end{array}$ & $\begin{array}{c}\text { Flight } \\
\text { Velocity } \\
(\mathbf{m} / \mathbf{s})\end{array}$ & $\begin{array}{c}\text { Spray Volume } \\
\text { Application } \\
\text { Rate }(\mathbf{L} / \mathbf{h a})\end{array}$ & $\begin{array}{c}\text { Effective } \\
\text { Flight } \\
\text { Distance } \\
(\mathbf{m})\end{array}$ \\
\hline $1 \#$ & $0.5 / \mathrm{NE}$ & 17.9 & 70.1 & 12.11 & 16.89 & 12.83 & 135.14 \\
$2 \#$ & $0.9 / \mathrm{N}$ & 17.2 & 72.1 & 10.87 & 17.58 & 18.49 & 140.65 \\
$3 \#$ & $1.2 / \mathrm{NE}$ & 16.4 & 74.8 & 11.65 & 16.36 & 28.58 & 130.86 \\
\hline
\end{tabular}

\subsubsection{Spray Droplet Size of Each Test}

The essence of the droplet deposition is that the droplets move in all directions after being released by the nozzle, and the movement trajectories of the droplets of different particle sizes are also different. The research on the droplets size distribution in the spraying area can provide the direct reference for the design and selection of the aviation nozzle to reduce the drift and improve the utilization rate of the pesticide. Figure 7 is the result of the droplet size distribution of each sampling line. As can be seen from Figure 7 , the maximum values of $D_{V 0.1}, D_{V 0.5}$, and $D_{V 0.9}$ appeared on the collecting line 3\#-1 and were $406 \mu \mathrm{m}, 728 \mu \mathrm{m}$, and $1179 \mu \mathrm{m}$, respectively. The minimum values of $D_{V 0.1}, D_{V 0.5}$, and $D_{V 0.9}$ were all found on sampling line 1\#-1 and were $152 \mu \mathrm{m}, 382 \mu \mathrm{m}$, and $617 \mu \mathrm{m}$, respectively.

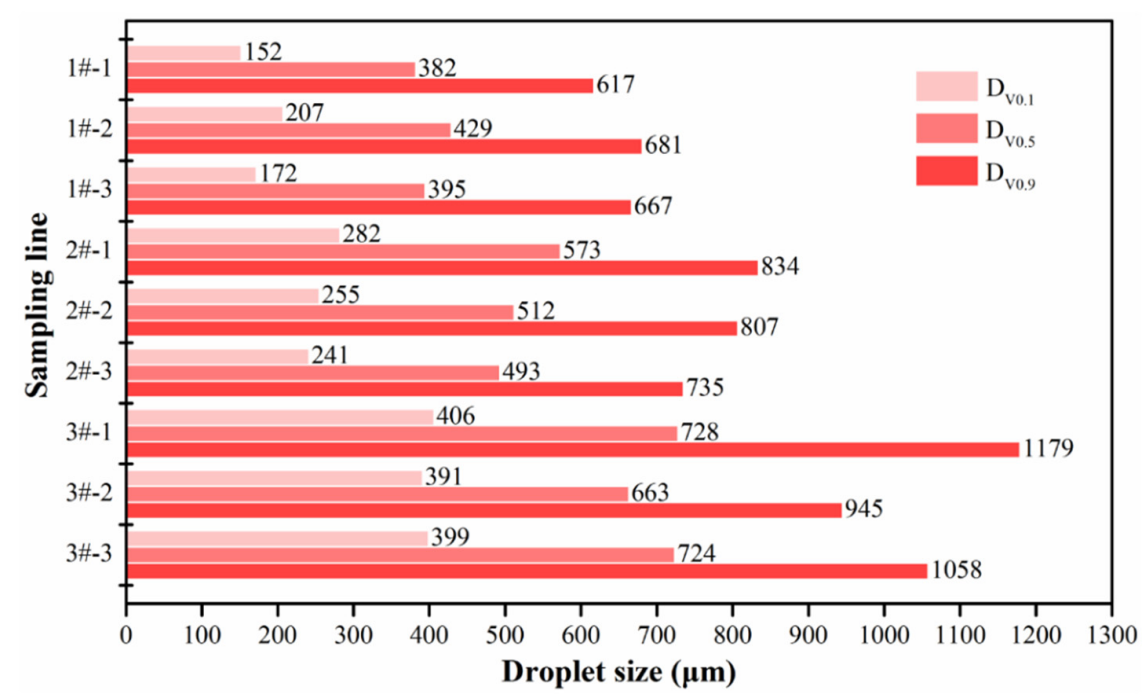

Figure 7. Droplet size distribution for each sampling line of each test. 
Compared the results in Figure 7 with the test results in the wind tunnel in Section 3.1.2, there was a big difference in $D_{V 0.1}, D_{V 0.5}$, and $D_{V 0.9}$, and the droplet size of each nozzle in the field test was significantly higher. The reason for this significant difference was due to the droplet size measurement method. The instrument used in the wind tunnel was an LDD, the optical detection method was used to capture the diffraction signal or light scattering signal generated by the laser dispersed particles in the liquid to perform particle statistics, then determining the droplets size. The accuracy of the measurement result was higher [30,31]. The field test was to analyze the droplet size on the WSP by image processing. However, due to the low flying velocity set in the field test, under the same spraying flow, the medium-low velocity spraying produced more droplets deposition than the high-velocity flying operation, which would lead to the higher density of droplets collected by the WSP. The high drop density was particularly pronounced when using CP04 nozzles with large orifice size. In addition, the WSP itself was extremely hydrophilic, and when the surface was excessively misty, diffusion or spot overlap was likely to occur. However, the existing droplet image processing technology was difficult to realize the droplet segmentation count and overlapping droplet identification, which resulted in a larger particle size value measured in the field test [32]. At the same time, it had been shown that the droplet image processing software DepositScan measured the droplets size to a certain extent larger than the standard value, especially when the droplet coverage on WSP was high, the deviation would be exceptionally obvious $[33,34]$. This also revealed the shortcomings of the WSP test application in some special operating environment. In the future, it is necessary to improve the image processing algorithm to promote the measurement accuracy or explore a kind of new type of spray test for medium-low velocity aircraft spraying instead of the current test methods.

In addition to the above reasons, the fixed measurement method of the LDD and tested nozzle to be measured during the wind tunnel test was also a reason for the large difference of droplet size. The wind tunnel test described in this article was limited by the conditions of the wind tunnel spray equipment at that time, and the nozzles could not move up and down in the wind tunnel. The LDD only measured the center position of the spray plume, and lacked the measurement of the entire spray plume. According to the existing studies, the droplet size at the center of the spray plume was smaller than the droplet size at the edge of the spray plume $[8,12]$. Therefore, the droplet size measured by the wind tunnel test in this paper was smaller in general, and the gap with the field test was more obvious. In the future, we will further optimize the wind tunnel spray equipment to achieve the overall measurement of the spray plume, and then obtain more accurate test results.

\subsubsection{Droplet Distribution in Spray Area}

In order to further describe the droplets distribution, the droplet sizes were divided into 0-100 $\mu \mathrm{m}$, 100-200 $\mu \mathrm{m}, 201-300 \mu \mathrm{m}, 301-400 \mu \mathrm{m}, 401-500 \mu \mathrm{m}$, and more than $500 \mu \mathrm{m}$. The droplet parameters of each sampling point were counted, and Figure 8 is the ratio of the droplet size spectrum of the three types of nozzles and the corresponding deposition and coverage. According to the calculation, the proportion of the droplets in the particle size spectrum of the CP02 nozzle in all droplets were $43.69 \%, 19.14 \%, 10.08 \%, 7.44 \%, 5.80 \%$, and $13.84 \%$, respectively. CP03 nozzle were $27.76 \%, 21.46 \%$, $13.40 \%, 9.59 \%, 7.68$, and $20.11 \%$ respectively, CP04 nozzle were $30.55 \%, 21.56 \%, 11.91 \%, 7.54 \%, 5.93 \%$, and $22.52 \%$. It can be clearly found that $62.83 \%$ of the droplets of the CP02 nozzle were distributed in the small particle size spectrum of less than $200 \mu \mathrm{m}$; the droplets of the CP03 nozzle occupied a relatively high range in the particle size spectrum of 201-500 $\mu \mathrm{m}$; for the CP04 nozzle, the droplets in the large particle size range of more than $500 \mu \mathrm{m}$ were relatively high. This was also consistent with the results of the wind tunnel particle size test, which enhanced the reliability of the test results. In addition, the study also found that the uniformity of the droplet size distribution between the sampling points in the field test area was poor, that is, the coefficient of variation was large. Taking the $3 \#$ as an example, the $C V$ of the CP04 nozzle in the droplet size spectrum were $51.37 \%, 22.81 \%, 33.50 \%$, $35.13 \%, 38.10 \%$, and $41.86 \%$, respectively, which exposed the common problem of strong randomness and poor reproducibility in the field test [28]. 


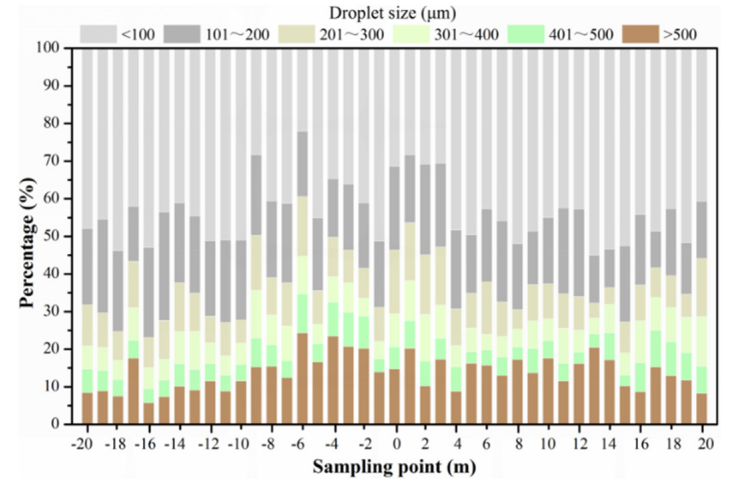

(a)

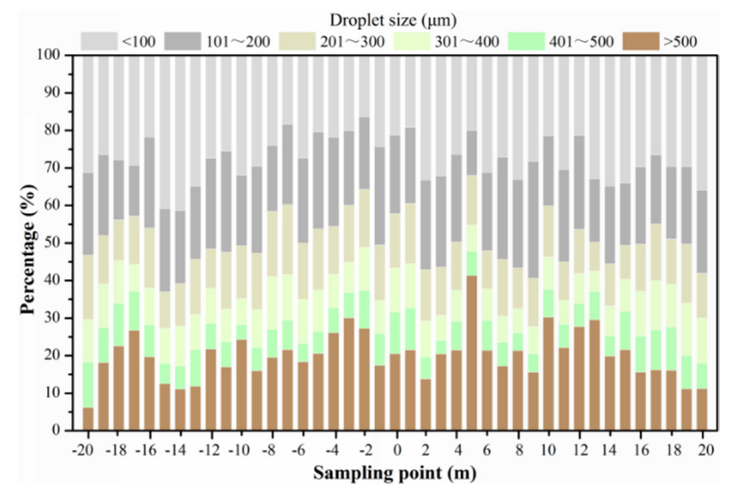

(c)

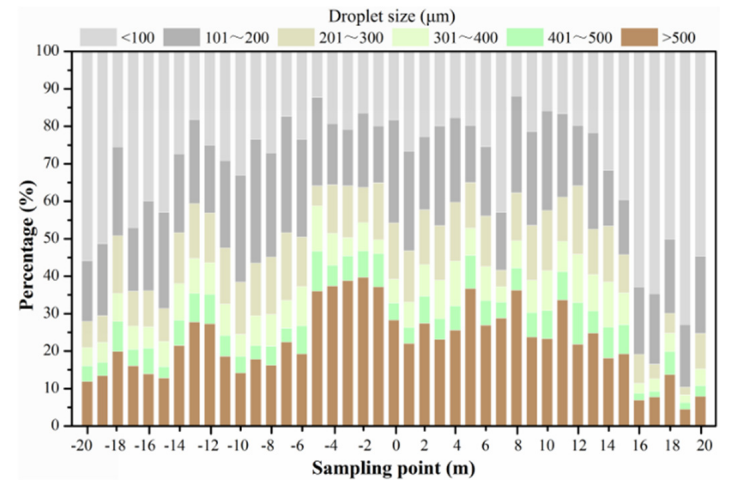

(e)

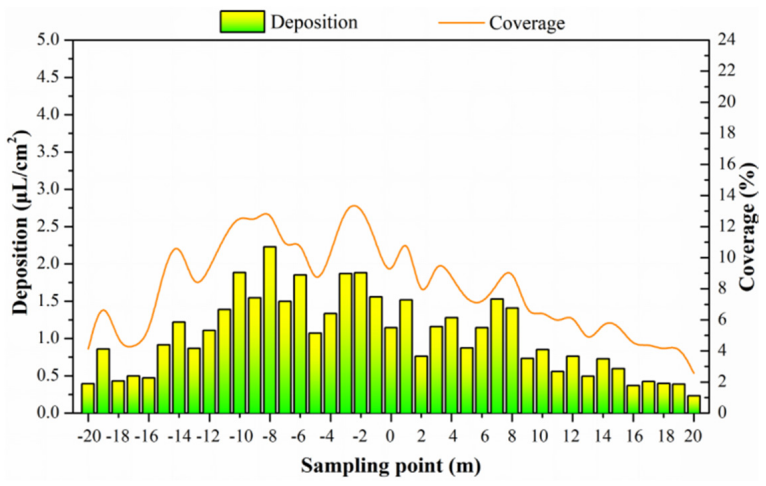

(b)

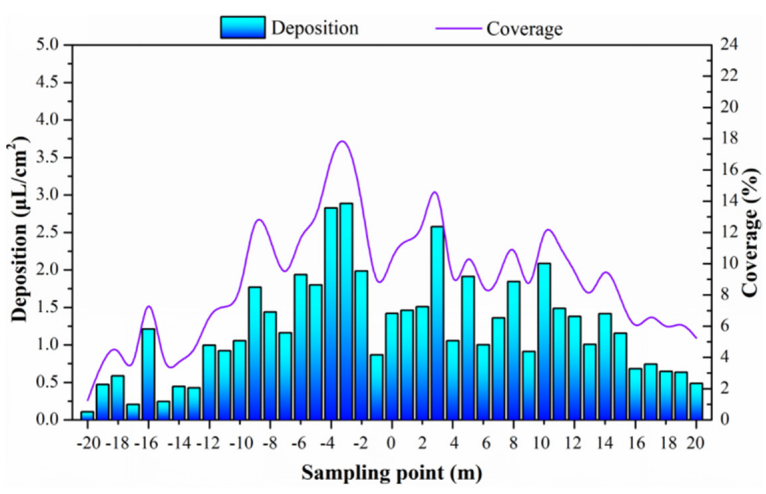

(d)

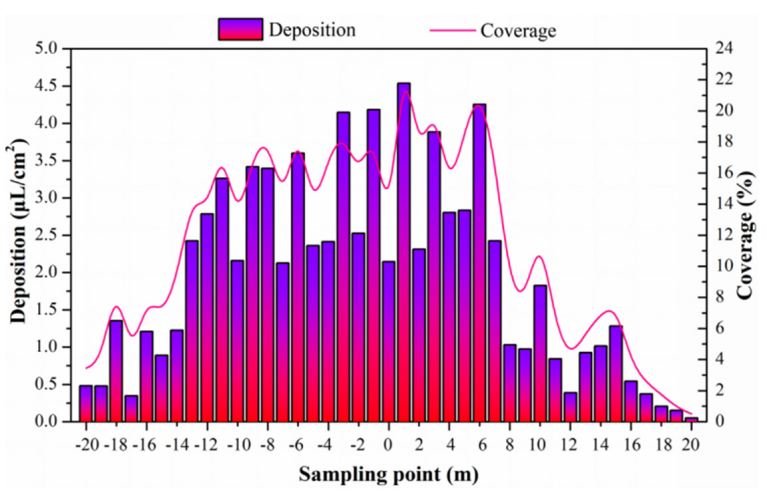

(f)

Figure 8. (a) Droplet size spectrum percentage of test $1 \#$ in the spray area; (b) deposition and coverage of test $1 \#$ in the spray area; (c) droplet size spectrum percentage of test $2 \#$ in the spray area; (d) deposition and coverage of test $2 \#$ in the spray area; (e) droplet size spectrum percentage of test $3 \#$ in the spray area; (f) deposition and coverage of test $3 \#$ in the spray area.

The droplet deposition and coverage at each sampling point are also important evaluation parameters for the distribution of droplets. Through observation, it can be found that from the sampling position of $-20 \mathrm{~m}$ to $20 \mathrm{~m}$, the deposition and coverage of each test showed similar trends. After calculation, the average droplet deposition and coverage of each test were $1.043 \mu \mathrm{L} / \mathrm{cm}^{2}, 8.04 \%$ (CP02 nozzle), $1.248 \mu \mathrm{L} / \mathrm{cm}^{2}, 8.89 \%$ (CP03 nozzle), and $1.975 \mu \mathrm{L} / \mathrm{cm}^{2}, 11.47 \%$ (CP04 nozzle), respectively. At the same time, the distribution of droplet deposition and coverage at each sampling point were also not very uniform. It can be seen that the droplet deposition and coverage near the helicopter route were significantly higher than those far from the route. In addition, by comparing with the droplet 
size spectrum percentage, it can also be found that the sampling locations where the deposition and coverage were higher, the proportion of large droplets size measured was also relatively high, which was obvious, so that the above-mentioned droplet size distribution results can be further explained.

\section{Conclusions}

In this study, the droplet size of three types of $\mathrm{CP}$ aviation nozzles adapted to manned agricultural helicopters were tested in both wind tunnel and actual flight conditions, and the droplet size distribution of these three types of $\mathrm{CP}$ aerial nozzles was analyzed under the condition of medium-low airflow velocity, the relatively accurate droplet size distribution characteristics were obtained. The conclusions were as follows:

(1) The wear caused by the long-time use of the nozzle will affect the spraying performance, which made the measurement deviation of droplet size value large. The maximum $D_{V 0.9}$ deviation between different nozzles of the same type nozzle was up to $259.4 \mu \mathrm{m}$.

(2) The limitation of wind tunnel droplet size measurement by using LDD was also found. At corresponding spray pressures of $345 \mathrm{kPa}(\mathrm{CP} 02), 330 \mathrm{kPa}(\mathrm{CP} 03)$, and $310 \mathrm{kPa}$ (CP04), the droplet size values measured by the three types of $\mathrm{CP}$ nozzles showed an increasing trend with the airflow velocity increased, and the value of $V_{<100}\left(\%_{\text {vol }}\right)$ showed a trend of decreasing gradually, while the $R S$ had no obvious regular change.

(3) The field test proved the main distribution range of each type nozzle droplet size, $62.83 \%$ of the droplets of the $\mathrm{CP} 02$ nozzle were distributed in the small particle size spectrum of less than $200 \mu \mathrm{m}$; the droplets of the CP03 nozzle occupied a relatively high range in the particle size spectrum of 201-500 $\mu \mathrm{m}$; for the CP04 nozzle, the droplets in the large particle size range of more than $500 \mu \mathrm{m}$ were relatively high, which was consistent with the results of wind tunnel test. The values of $D_{V 0.1}$, $D_{V 0.5}$, and $D_{V 0.9}$ of the three types nozzles measured in the field test were significantly higher than those in the wind tunnel test, but the results can be used as a reference for each other.

The experiment demonstrated that it is necessary to strictly control the quality of the nozzles in selection, try to control the droplets size parameters within a suitable range, and reduce the spray deviation to achieve the optimal spraying effect.

Author Contributions: Conceptualization, W.Y., Y.L., and W.C.H.; methodology, W.Y.; software, W.Y.; validation, J.L., S.G., and J.W.; formal analysis, W.Y.; investigation, W.Y.; resources, Y.L.; data curation, W.Y.; writing—original draft preparation, W.Y., W.C.H., and H.Z.; writing-review and editing, W.Y. and S.G.; visualization, Y.L.; supervision, Y.L.; project administration, Y.L.; funding acquisition, Y.L. All authors have read and agreed to the published version of the manuscript.

Funding: This research was funded by the Guangdong Leading Talent Project, grant number 2016LJ06G689, National Key Technologies Research and Development Program, grant number 2016YFD0200700, 111 Project, grant number D18019.

Acknowledgments: Thanks to the National Center for International Collaboration Research on Precision Agricultural Aviation Pesticides Spraying Technology for the full participation persons of the experiment (Yan Yingbin, Li Zhihong, Meng Yanhua, Chen Pengchao, Zhang Quanyong, Huang Xiaoyu). Thanks to Jiangxi Tianren Ecology Co., Ltd and Ji'an Polytechnic for strong support.

Conflicts of Interest: The authors declare no conflict of interest.

\section{References}

1. Lan, Y.B.; Chen, S.D.; Fritz, B.K. Current status and future trends of precision agricultural aviation technologies. Int. J. Agric. Biol. Eng. 2017, 10, 1-17.

2. Yao, W.; Wang, X.; Lan, Y.; Jin, J. Effect of UAV prewetting application during the flowering period of cotton on pesticide droplet deposition. Front. Agric. Sci. Eng. 2018, 5, 455-461. [CrossRef]

3. Hilz, E.; Vermeer, A.W.P. Spray drift review: The extent to which a formulation can contribute to spray drift reduction. Crop Prot. 2013, 44, 75-83. [CrossRef] 
4. Wang, G.; Lan, Y.; Yuan, H.; Qi, H.; Chen, P.; Ouyang, F.; Han, Y. Comparison of spray deposition, control efficacy on wheat aphids and working efficiency in the wheat field of the unmanned aerial vehicle with boom sprayer and two conventional knapsack sprayers. Appl. Sci. 2019, 9, 218. [CrossRef]

5. Fritz, B.K.; Hoffmann, W.C. Establishing reference nozzles for classification of aerial application spray technologies. Int. J. Precis. Agric. Aviat. 2018, 1, 10-14. [CrossRef]

6. Hewitt, A.J. Droplet size spectra classification categories in aerial application scenarios. Crop Prot. 2008, 27, 1284-1288. [CrossRef]

7. Lan, Y.; Peng, J.; Jin, J. Research status and development of pesticide spraying droplet size. J. South China Agric. Univ. 2016, 37, 1-9.

8. Hoffmann, W.C.; Fritz, B.K.; Lan, Y.B. Using laser diffraction to measure agricultural sprays: Common sources of error when making measurements. Int. J. Precis. Agric. Aviat. 2018, 1, 15-18. [CrossRef]

9. Nuyttens, D.; Schampheleire, M.D.; Verboven, P.; Sonck, B. Comparison between indirect and direct spray drift assessment methods. Biosyst. Eng. 2010, 105, 2-12. [CrossRef]

10. Liu, H.; Lan, Y.; Xue, X.; Zhou, Z.; Luo, X. Development of wind tunnel test technologies in agricultural aviation spraying. Trans. CSAE 2015, 31, 1-10.

11. Kirk, I.W. Measurement and prediction of atomization parameters from fixed-wing aircraft spray nozzles. Trans. ASABE 2007, 50, 693-703. [CrossRef]

12. Hoffmann, W.C.; Hewitt, A.J.; Ross, J.B.; Bagley, W.E.; Martin, D.E.; Fritz, B.K. Spray adjuvant effects on droplet size spectra measured by three laser-based systems in a high-speed wind tunnel. J. ASTM Int. 2008, 5,1-12. [CrossRef]

13. Azizpanah, A.; Rajabipour, A.; Alimardani, R.; Kheiralipour, K.; Mohammadi, V. Precision spray modeling using image processing and artificial neural network. Agric. Eng. Int. CIGR J. 2015, 17, 65-74.

14. Dorr, G.; Hanan, J.; Adkins, S.; Hewitt, A.; O'Donnell, C.; Noller, B. Spray deposition on plant surfaces: A modelling approach. Funct. Plant Biol. 2008, 35, 988-996. [CrossRef]

15. Ferguson, J.C.; Chechetto, R.G.; Hewitt, A.J.; Chauhan, B.S.; Adkins, S.W.; Kruger, G.R.; O’Donnell, C.C. Assessing the deposition and canopy penetration of nozzles with different spray qualities in an oat (Avena sativa L.) canopy. Crop Prot. 2016, 81, 14-19. [CrossRef]

16. Ferguson, J.C.; Chechetto, R.G.; O’Donnell, C.C.; Dorr, G.J.; Moore, J.H.; Baker, G.J.; Powis, K.J.; Hewitt, A.J. Determining the drift potential of Venturi nozzles compared with standard nozzles across three insecticide spray solutions in a wind tunnel. Pest Manag. Sci. 2016, 72, 1460-1466. [CrossRef]

17. Guler, H.; Zhu, H.; Ozkan, H.E.; Derksen, R.C.; Yu, Y.; Krause, C.R. Spray characteristics and drift reduction potential with air induction and conventional flat-fan nozzles. Trans. ASABE 2007, 50, 745-754. [CrossRef]

18. Ru, Y.; Zhu, C.; Bao, R.; Li, Z.; Ding, T. Droplet size distribution of aerial nozzle for plant protection in wind tunnel and flight conditions. Trans. CSAE 2016, 32, 94-98.

19. Fritz, B.K.; Hoffmann, W.C.; Wolf, R.E.; Bretthauer, S.; Bagley, W.E. Wind tunnel and field evaluation of drift from aerial spray applications with multiple spray formulations. J. ASTM Int. 2013, 32, 96-113.

20. Li, J.; Guo, S.; Yao, W.; Zhan, Y.; Li, Y. Distribution characteristics of droplet size in rice field and wind tunnel simulation test under airflow operation. Trans. CSAM 2019, 50, 148-156.

21. Zhang, D.Y.; Chen, L.P.; Zhang, R.R.; Xu, G.; Lan, Y.B.; Hoffmann, W.C.; Wang, X.; Xu, M. Evaluating effective swath width and droplet distribution of aerial spraying systems on M-18B and Thrush 510G airplanes. Int. J. Agric. Biol. Eng. 2015, 8, 21-30.

22. Guo, S.; Li, J.; Yao, W.; Zhan, Y.; Li, Y.; Shi, Y. Distribution characteristics on droplet deposition of wind field vortex formed by multirotor UAV. PLoS ONE 2019, 14, e0220024. [CrossRef] [PubMed]

23. Yao, W.; Lan, Y.; Wang, J.; Wen, S.; Wang, G.; Chen, S. Droplet drift characteristics of aerial spraying of AS350B3e helicopter. Trans. CSAE 2017, 33, 75-83.

24. Yao, W.X.; Lan, Y.B.; Wen, S.; Zhang, H.H.; Zhang, Y.L.; Wang, J.; Xie, C.C. Evaluation of droplet deposition and effect of variable-rate application by a manned helicopter with AG-NAV Guía system. Int. J. Agric. Biol. Eng. 2019, 12, 172-178.

25. Zhang, D.; Lan, Y.; Chen, L.; Wang, X.; Liang, D. Current status and future trends of agricultural aerial spraying technology in China. Trans. CSAM 2014, 45, 53-59.

26. ISO/TC23/SC6. Equipment for Crop Protection-Methods for the Laboratory Measurement of Spray Drift-Wind Tunnels; ISO Copyright Office: Geneva, Switzerland, 2008; ISO 22856. 
27. Fritz, B.K.; Hoffmann, W.C.; Bagley, W.E.; Kruger, G.R.; Czaczyk, Z.; Henry, R.S. Measuring droplet size of agricultural spray nozzles-measurement distance and airspeed effects. At. Sprays 2014, 24, 747-760. [CrossRef]

28. Hsiang, L.P.; Faeth, G.M. Drop properties after secondary breakup. Int. J. Multiph. Flow 1993, 19, 721-735. [CrossRef]

29. Tang, Q.; Chen, L.; Zhang, R.; Zhang, B.; Yi, T.; Xu, M.; Xu, G. Atomization characteristics of normal flat fan nozzle and air induction nozzle under high speed airflow conditions. Trans. CSAE 2016, 32, 121-128.

30. Dodge, L.G.; Rhodes, D.J.; Reitz, R.D. Drop-size measurement techniques for sprays: Comparison of malvern laser-diffraction and aerometrics phase/doppler. Appl. Opt. 1987, 26, 2144-2154. [CrossRef]

31. Womac, A.R. Quality Control of Standardized Reference Spray Nozzles. Trans. ASAE 2000, 43, 47-56. [CrossRef]

32. Cunha, M.; Carvalho, C.; Marcal, A.R.S. Assessing the ability of image processing software to analyse spray quality on water-sensitive papers used as artificial targets. Biosyst. Eng. 2012, 111, 11-23. [CrossRef]

33. Zhu, H.; Masoud, S.; Robert, D.F. A portable scanning system for evaluation of spray deposit distribution. Comput. Electron. Agric. 2011, 76, 38-43. [CrossRef]

34. Fox, R.D.; Derksen, R.C.; Cooper, J.A.; Krause, C.R.; Ozkan, H.E. Visual and image system measurement of spray deposits using water-sensitive paper. Appl. Eng. Agric. 2003, 19, 549-552.

(C) 2020 by the authors. Licensee MDPI, Basel, Switzerland. This article is an open access article distributed under the terms and conditions of the Creative Commons Attribution (CC BY) license (http://creativecommons.org/licenses/by/4.0/). 